\title{
Pancreas
}

EFFECT OF INTRADUODENAL ADMINISTRATION OF OVALBUMIN (OVA) AND HCI VS. INTRAVENOUS INFUSION OF CCK 33 AND SECRETIN ON EXOCRINE PANCREATIC SECRETION IN PIGS AROUND WEANING. S. G. Pierzynowski. M-J. Thaela, B. W. Weström, J. Svendsen, B. W.Karlsson. Dept. of Animal Physiology, University of Lund, Lund, Sweden.

In early mammalian postnatal life milk exhibits low stimulatory effects on the exocrine pancreas function as compared to the effects of solid food in adults. Moreover, in newborn and young mammals the pancreatic in adults. Moreover, in newborn and young mammals the pancreatic low potency to stimulate the exocrine pancreas.

In order to study the development of regulatory mechanisms of the exocrine pancreas, 11 pigs were surgically prepared 2 weeks before weaning for long-term collection of pancreatic jüice. Experiments (lasting for $2.5 \mathrm{~h}$ ) were performed every second day, starting two days after the surgical procedures and 2 days after weaning (performed at 4 weeks of age). Pancreatic juice was collected in plastic tubes on ice bath, during 15 min intervals. After a baseline period (the first $30 \mathrm{~min}$ ), thirty minutes control infusions of either $5 \mathrm{ml}$ saline $/ \mathrm{kg} / \mathrm{h}$ intraduodenally (i.d.) or $2 \mathrm{ml}$ saline $+0.5 \% \mathrm{BSA} / \mathrm{kg} / \mathrm{h}$ intravenously (i.v.) were done, followed by treatment $(3 \times 30 \mathrm{~min}$.) with increasing doses of: OVA $(5,50,500 \mathrm{mg} / \mathrm{kg} / \mathrm{h}$, $\mathrm{mmol} / \mathrm{kg} / \mathrm{h}$, i.d. ) or secretin $(22,110,440 \mathrm{pmol} / \mathrm{kg} / \mathrm{h}$, i.v.). All treatments were performed once before and two times after weaning.

I.d. infusion of OVA and i.v. administration of CCK 33 did not affect pancreatic exocrine secretion, whereas i.d. $\mathrm{HCl}$ infusion before weaning stimulated pancreatic juice outflow from 1.1 to $2.1 \mathrm{ml} / \mathrm{kg} / \mathrm{h}$ and after weaning from 2 to $3.5 \mathrm{ml} / \mathrm{kg} / \mathrm{h}$. The protein output increased from 2.5 to $4.0 \mathrm{mg} / \mathrm{kg} / \mathrm{h}$.

Secretin i.v. infusion stimulated the volume outflow from 1 to $2 \mathrm{ml} / \mathrm{kg} / \mathrm{h}$ before weaning and from 2 to $6 \mathrm{ml} / \mathrm{kg} / \mathrm{h}$ after weaning and the protein output from 2.5 to $6 \mathrm{mg} / \mathrm{kg} / \mathrm{h}$. Trypsin activity outflow was slightly stimulated from 1 to $2 \mathrm{U} / \mathrm{kg} / \mathrm{h}$ before weaning but from 3 to $6 \mathrm{U} / \mathrm{kg} / \mathrm{h} 3-4$ weeks after weaning.

In conclusion, the secretin and $\mathrm{HCl}$ dependent stimulatory mechanisms of the exocrine pancreas are already in function before weaning in pigs, though the effects are enhanced after weaning. Surprisingly i.d. infusion of the protein OVA and i.v. administration of CCK 33 did show very low, if any, stimulatory effects on exocrine pancreas neither before nor after weaning.

PANCREATIC ELASTASE (E1) IN FECES: A NEW TUBELES PANCREATIC FUNCTION TEST. W.E. DOppl, H. SchnellKretschmer, *A. Sziegoleit, ${ }^{\star H}$.Schäfer, H.U. Klör, $\mathrm{K}$. Federlin. $3^{\text {Id }}$ Dept. of Internal Medicine, *Dept. of Microbiology. Justus-Liebig-University of Giessen, Germany.

The proteolytic pancreatic enzyme $\mathrm{El}$ has a striking in vivo and in vitro stabilitity and appears nearly unchanged in the feces. Because of a lack of sensitive, adequately evaluated and feasible tests of pancreatic function, we investigated $\mathrm{El}$ in the feces

424 stool samples from 136 individuals were diluted and $E 1$ was measured quantitativly by an enzyme-linked immunosorbent assay using monoclonal antibodies (Clin. Bioch. 1989,22:85-89). The results were compared with the Monotest Chymotrypsin (Fa. Boehringer Mannheim) and the Pancreolauryl-Test (PLT) (Fa. Temmler, Marburg, Germany), two available indirect pancreatic function tests. The reference values of El: pathological pancreatic function when El $100 \mathrm{mg} / \mathrm{g}$ feces, borderline function from 100 up to $200 \mathrm{mg} / \mathrm{g}$ feces-and normal exocrine function when E1 > $200 \mathrm{mg} / \mathrm{g}$ feces.

Activity levels of E1, Chymotrypsin and PLT agreed in $88(62,48)$ cases, only of $\mathrm{E} 1$ and Chymotrypsin in $108(79,48)$ cases and of E1 and PLT in $103(75,78)$ cases.

There is a good correlation between $E 1$ and other established indirect exocrine function tests. Quantitative determination of stool-El by ELISA is advantageous as compared with Chymotrypsin and PLT because of lack of interference by pancreatic enzyme replacement therapy, high sensitivity and specificity and because of the possibility of automated analysis.

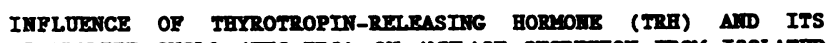
METABOLITE CYCLO (HIS-FRO) OI AMYTASE SBGRESIOI FROA ISOLATED RAT EXOCRINR PANGRRATIC ACIMAR CELLLS

T.P. Xemmer ${ }^{1}$, L. Duntas ${ }^{1}$, W. Munz ${ }^{1}$, P. Mnlfertheiner ${ }^{2}$

Dept. of Internal Medicine I, Oniversity of $01 \mathrm{~m}$, Germany

The exocrine pancreas contains high amounts of TRH, and exogenous TRH Inhibits in vivo pancreaticiprotein secretion in a dose-dependent manner (Gastroenterology 80, 735, 1981; Pancreas 5, 37, 1990). Aim of our study was to investigate a direct effect of TRH and its metabolite Crclo (His-Pro) on rat exocrine pancreatic acinar cells.

Methods: Isolated acinar cells from rat exocrine pancreas were obtained by a collagenase digestion technique. Amylase release from acinar cells was measured during a 40 min-incubation period at $37^{\circ} \mathrm{C}$ under basal and secretagogue-stimulated conditions. Results:- TRH did not affect basal amylase release in concen-
trations from $10^{-13} \mathrm{M}$ to $10^{-7} \mathrm{M}$. TRH inhibited carbachol $\left(10^{-5}\right.$ $M)$-stimulated amylase secretion by a maximum of $24 \mathrm{Z}$ at a concentration of $10^{-11} \mathrm{M}(\mathrm{p}<0.05)$. Ceruletide $\left(3 \times 10^{-10} \mathrm{M}\right)$ stimulated amylase secretion was maximally reduced by 232 at a TRH concentration of $10^{-10} \mathrm{M}(\mathrm{p}<0.05)$. Direct stimulation of proteinkinase $C$-mediated secretion by the diacylglycerol analog 1-oleoyl-2-acetyl-sn-glycerol (OAG, $5 \times 10^{-4} \mathrm{M}$ ) was-not-altered by TRH. The TRH metabolite Cyclo (His-Pro) did not influence basal or stimulated pancreatic secretion.

Conclusions: In contrast to the TRH metabolite Cyclo (HisPro) TRH shows a direct inhibitory effect on receptor-mediated stimulation of carbachol- and ceruletide-induced enzyme secretion, whereas proteinkinase C-mediated secretion is no influenced. These findings point to a TRH-induced modulation of exocrine pancreatic secretion at the receptor site.
MTTRIC OTIDE (BO)-PRODUCIBG GEURONS IR TEE MAYOAALIAK PABCREAS. R.De Giorgio, NC.Brecha"^, A.TuCCI, R.Corinaldesi, I.Franzoso, VLW.GO^, C.Sternini^*. Institute of Internal Medicine Gastroenterology, University of Bologna, Italy; "Depts. of Anatomy Cell Biology, and "Medicine; \# CURE, VAMC-Wadeworth, UCLA School of Medicine, LOs Angeles, CA, USA.

One of the major neuronal supply of the mammalian pancreas is represented by the non-adrenergic, non-cholinergic component. so, a newly identified putative neurotransmitter, is able to stimulate the exocrine secretion in the isolated porcine pancreas and to induce insulin release. The formation of No is dependent upon the activation of the constitutive enzyme No synthase, which is identical to NADPH-diaphorase (NADPB-D). Using NADPE-D. histochemical technique, we evaluated 1) whether the pancreatic innervation includes - vo-containing neurons; and 2) the possible targets of NADPB-D positive nerves. Pancreatic tissues from cats, dogs, pigs, monkeys (Hacaca Cebius) and humans (normal transplant donors) were fixed in zamboni's solution and cryoprotected in 258 sucrose. Tissues were sectioned $(10-15 \mu \mathrm{m})$ with a cryostat and stained with NADPB-D technique. NADPB-labeled nerves and neuronal cell bodies were identified in each of the mammalian pancreas examined. Overall, NADPB-D nerve processes were particularly abundant throughout the acini with the following density: cat and pig > dog and monkey > buman. In all species, the intrapancreatic ganglia showed numerous neuronal cell bodies positive for NADPB-D. The density of NADPH-D labeled neurons was: cat and monkey > dog and pig > human. The vasculature, ducts and endocrine tissue showed the least abundant NADPB-D innervation. There were no evident differences among the species studied except for the pig islets where NADPB-D nerve endings were not detectable.

In conclusion, our results showed that: 1) No-producing neurons are a major component of the pancreatic innervation and 2) the identification of intraparenchymal neurons markedly reactive for an intringic origin of NADPB-D positive nerves. The diversity af intringic origin of the targets of No containing nerves in the pancreas 
ROLE OF VARIOUS PHOSPHOLIPASES-A2 (PLA-2) AND INHIBITORS IN THE PATHOGENESIS AND TREATMENT OF ACUTE EXPERIMENTAL PANCREATITIS. J.MOSSner, C.WESsig, W. Fischbach. Med.Poliklinik. Univ. of Wüzburg, FRG.

We have reported that lipolytic enzymes, such as lipase and PLA-2, by their ability to release fatty acids and lysolecithin may destroy pancreatic acinar cells (Pancreas 1992;8:70). We now studied which form of PLA-2 is responsible for cellular damage and how to inhibit its action. Isolated rat pancreatic acini were prepared by collagenase digestion. Newly synthesized proteins were labeled by incubation of cells with 35-5-methionine. Acini were further incubated in buffer to which various factors, such as pure pancreatic - RLA-Z, bee-venom
PLA-2, homogenates of leukocytes, homogenates of PLA-2, homogenates of leukocytes, homogenates of
pancreas all $+/-$ lecithin and $+/-$ potential inhibitors (nafamostat-mesilate, aprotinin, CDP-choline, BM 16.2115, quinacrin, albumin) were added. Cellul'ar destruction was measured by the degree of release of radiolabeled proteins. PLA $=2$ alone was not harmful within $30 \mathrm{~min}$ of incubation. However. incubation of acini with either bee-venom or-pancreatic PLA-2 in combination with Tecithin caused rapid cellular destruction. Addition of high concentrations of trypsin activated pancreatic homogenates both alone and + lecithin caused cellular destruction suggesting that pancreatic PLA-2 uses lecithin from pancreatic membranes as substrate. Homogenates of leukocytes were not able to destroy isolated pancreatic acini due to a much lower PLA-2 concentration as compared to the PLA-2 content present in pancreatic homogenates. All inhibitors tested besides albumin were not able to inhibit the destruction caused by pancreatic PLA-2 and lecithin. Conclusion: Pancreatic PLA-2 and not PLA-2 from infiltrating leukocytes may play a role in cellular necrosis of acute pancreatitis provided that its substrate lecithin is present. Lecithin may originate from cellular membranes destroyed by other mechanisms. For further studies in vivo one needs specific ron toxic inhibitors of pancreatic PLA-2 which are not available yet.
A SINGLE AND NON INVASIVE SCINTIGRAPHYC PROCEDURE TO LOCALIZE GASTRO-ENTERO-PANCREATIC (GEP) TUMORS. V. Corleto, G. Delle Fave, F. Scopinaro*, O. Schillaci*, L. Di Macio*, E. Polettini*, G. Gualdi*, M. Marignani, B. Annibale. Departments of Gastroenterology, *Nuclear Medicine and "Intemal Medicine,University "La Sapienza" Roma.

Recently, a radiolabeled somatostatin analogue (111 In-pentetreotide, "OctreoScan 111", Mallinckrodt Diagnostica, Petten Holland) has been proposed for "in vivo" detection of somatostatin-receptor bearing tumors. We have investigated the diagnostic efficacy of OctreoScan 111 scintigraphy to localize tumor lesions in 19 patients with biochemical (18/19) and/or histological (6/19) diagnosis of GEP-tumor (gastrinomas: 13; carcinoids: 2; somatostatinomas: 2; Vip-oma: 1; Men-II: 1;). Each patient was studied 4, 24 and 48 hours after injection of 180-220 MBq of OctreoScan 111. Total body planar and SPET abdominal imagings were performed using a gamma camera (Starcam 2000,G.E., Milwaukee, USA) equipped with a medium energy parallel collimator. The scintigraphic results were compared with CT (Philips Tomoscan LX) and MR (Philips Gyroscan T5) imagings performed within one month. Results: The same findings were observed in the planar and SPET imagings obtained at 4, 24 and 48 hours after OctreoScan 111 injection, indicating that early imagings were not affected by interfering background radioactivity. OctreoScan 111 detected tumor lesions in all patients except the patient with MEN-II, who at the time of the study had-non-active disease-because previously had tumor lesions (pheocromocytoma and non functional pancreatic tumor) resected. A single abdominal localization was visualized in 9 out of 13 patients with ZES, of whom 5 had tumors located in the liver and 4 in pancreatic-duodenal region, in the remaining 4 patients multiple abdominal localizations were observed. $\mathrm{CT}$ and $\mathrm{MR}$ respectively visualized lesions in 5 out of $13(38,5 \%)$ and-in 7 out of $13(53,8 \%)$ patients, size $0.7-2.5 \mathrm{~cm}$.; all these lesions were also detected by OctreoScan 111 scintigraphy. The two somatostatinomas, one carcinoid and the VIP-oma patient had multiple hepatic and/or abdominal multiple extrahepatic lesions observed with OctreoScan and CT. In addition OctreoScan visualized a metastatic hepatic lesion in the other carcinoid patient and two chest lesions in VIP-oma patient, both were not observed with CT. The diagnostic advantages of 111 In-pentatreotide compared with other imagings techniques are probably due to the capability of OctreoScan 111 to visualize, indipendently from size, tumoral lesions having somatostatin receptors. These data suggest that this single and non invasive diagnostic procedure is able to successefully localize primary and/or metastatic lesions and could be the first imaging study to be performed in all GEP-tumors.
MORPHOLOGICAL AND MOLECULAR EVIDENCE FOR AN EPIDERMAL GROWTH FACTOR RECEPTOR AUTOCRINE LOOP IN CHRONIC PANCREATITIS. H. Friess, Y. Yamanaka, M. Bllchler, M.S. Kobrin, H.G. Beger, M. Korc. Depts. of Medicine and Biol. Chem., Univ. of California, Irvine, USA; Dept. of Surgery, Univ. of Ulm, Germany.

The biochemical and molecular mechanisms that underlie the pathophysiology of chronic pancreatitis (CP) are completely unknown. Recently, transforming growth factor alpha (TGF- $\alpha$ ) overexpressing transgenic mice have been found țo exhibit CP-like histological changes in the pancreas. TGF- $\alpha$ binds and activates the epidermal growth factor receptor (EGFR). Therefore, we analysed TGF- $\alpha$ and EGFR expression in human $\mathrm{CP}$ tissues.

Patients: CP tissue samples were obtained from 27 pats. (23 men, 4 women, median age: 43 (range 23-56) years) undergoing surgery for CP. 17 pancreas from healthy organ donors served as controls.

Methods: TGF- $\alpha$ and-EGFR expression was studied by immunohistochemistry, using specific monoclonal antibodies, and by in situ hybridization and Northern blot analysis, using specific CRNA probes.

Results: By immunohistochemistry, TGF- $\alpha$ and EGFR were expressed at high levels in both acinar cells and ductal cells in $\mathrm{CP}$ tissues. Northern blot analysis indicated, that by comparison with normal controls, 10 of $12 \mathrm{CP}$ tissues exhibited a 6.7-fold increase in TGF- $\alpha$ mRNA levels and 13 of 19 CP tissues exhibited a 6.0-fold increase in EGFR mRNA levels. In situ hybridization confirmed that overexpression occurred in both acinar and ductal cells, and indicated that both mRNA moieties co-localized with their respective proteins.

Conclusion: our findings suggest that TGF- $\alpha$ may act through autocrine and paracrine mechanisms to excessively activate the overexpressed EGFR in CP, thereby contributing to the histological and pathophysiological changes that occur in this disorder.

\section{OVIII/8 555}

DIAGNOSIS AND DIFFERENTIATION OF PANCREATIC TUMORS: COMPARISON OF ENDOSONOGRAPHY, COMPUTED TOMOGRAPHY AND MAGNETIC RESONANCE IMAGING. Ch. Mevenberger B. Marincek", R. Schaer Ph. Bertschinger, H.P. Wirth, Th. Bischof", R. Jost, R. Ammann, J. Altorfer. Depts. of Medicine (Gastroenterology Unit) and Radiology", University Hospital of Zurich, Switzerland.

Endoscopic ultrasound (EUS) has gained a central role in the diagnosis of pancreatic disease. The purpose of this study was to assess the value of EUS, computed tomography (CT) and magnetic resonance imaging (MR imaging) in diagnosing pancreatic tumor.

Patients and Methods: Sixty patients (26 f, $34 \mathrm{~m}$, mean age 60 yrs) with clinically suspected pancreatic tumor were evaluated in a prospective study with EUS $(n=60)$, CT $(n=52)$ and MR imaging $(n=28)$. EUS was performed with a $7.5 \mathrm{MHz}$ Olympus echoendoscope. The final diagnosis was made by surgery $(n=34)$, or biopsy $(n=10)$ combined with follow-up examinations ( $n=26$; mean follow-up 16 months ; range 11-26 months). There were 23 malignant, 8 benign and 9 inflammatory turnors. In 20 patients a tumor was excluded.

Besults: Sensitivity of EUS , CT and MR imaging in diagnosing pancreatic tumor was $93 \% ; 58 \%$ and $73 \%$, respectively. Specificity of EUS, CT. and MR imaging was $100 \% ; 64 \%$ and $100 \%$, respectively. The overall accuracy of EUS was $95 \%$; of CT $60 \%$; and of MR imaging $75 \%$. The sensitivity of EUS $(n=21), C T(n=20)$ and MR imaging ( $n=15)$ for small tumors $<3 \mathrm{~cm}(n=21)$ was $91 \%, 40 \%$ and $53 \%$, respectively. EUS correctly classified the inflammatory nature of the tumor in 7 of 9 patients (89 $\%)$ as proven by laparotomy $(n=4)$ or biopsy $(n=4)$ and follow-up examinations. The correct diagnosis was given by CT in 1 of 8 patients (13\%). MR imaging ( $n=3$ ) falsely classified all inflammatory lesions as malignant tumors.

Conclusion: 1.EUS was more accurate than CT and MR imaging in diagnosing pancreatic tumors. 2. EUS was significantly superior to CT-and MR imaging in detecting small pancreatic tumors. 3. Although all three modalities had limitations in the differentiation between malignancy and focal pancreatitis, EUS was superior to CT and MR imaging in this respect. 